\title{
Accident Prevention and Reporting System Using GSM (SIM 900D) and GPS (NMEA 0183)
}

\author{
Rashida Nazir, Ayesha Tariq, Sadia Murawwat*, Sajjad Rabbani \\ Department of Electrical Engineering, Lahore College for Women University, Lahore, Pakistan \\ Email: sadia.murawwat@hotmail.com
}

Received 9 June 2014; revised 9 July 2014; accepted 30 July 2014

Copyright (C) 2014 by authors and Scientific Research Publishing Inc.

This work is licensed under the Creative Commons Attribution International License (CC BY).

http://creativecommons.org/licenses/by/4.0/

(c) (i) Open Access

\section{Abstract}

The Rapid growth of technology has made our life easier. This advancement in technology also increased the traffic hazards. Hence the ratio of road accidents which take place frequently increases causing immense loss of life due to poor emergency facilities. Main causes behind these road accidents include: lack of training institutes, unskilled drivers, poor road conditions, use of cell phone during driving, over loading and poor governmental plans in this regard. Our research provides a solution for accident detection and prevention for human life safety. It enables intelligent detection of an accident at any place and reports about the accident on predefined numbers. Our system consists of two parts, alarming part and messaging part. The hardware includes SONAR ranging modules, vibration sensor, three modules GPS receiver (NMEA), Microcontroller (AT89S51), GSM modem (SIM 900D) and an Alarm. When distance is too short between the vehicle and obstacle then alarm will be "ON" as an indicator to move vehicle in other direction which is safer but when a vehicle faces accident despite of alarm, immediately vibration sensor will detect the signal and then Microcontroller sends the alert message through the GSM modem including the location to predefined numbers that can be reserved for a rescue team. Our designed system has been tested at different locations and found to be effectively working by sending alert messages to mobile phone user.

\section{Keywords}

Accident Protection, GSM Modem, GPS Modem, Sonar System, Vibration Sensor

\footnotetext{
${ }^{*}$ Corresponding author.
} 


\section{Introduction}

Rapid development of economic construction and people's living standard continues to improve well as road traffic accidents take place frequently, which causes huge losses of life and property to the country and people. The development of a transportation system has been the generative power for human beings to have the highest civilization above creature in the earth. Despite many efforts taken by different organizations all around the world by various programs to warn against careless driving, accidents have taken place every day. However, many lives could have been saved if the emergency service could get the crash information and proper help provided at time.

Although different organizations all around the world carry out workshops and other training programs to make people aware of careless driving, this whole process is not very successful till date. For example, according to WHO (Word Heath Rankings) data published in April 2001 Road traffic accidents death in Pakistan reached 2154 or $1.58 \%$ of total deaths [1] showed the situation. In developed countries, many accident prevention technologies have been used. Since Pakistan is an underdeveloped country and not very efficient in technology usage. It will prove beneficial in Pakistan because it is not using any advance technology i.e. airbags use in western countries to secure the accident victims [2]. This system can also use in that car which is using technology of air bag because sometimes air bag doesn't open and accident victim gets injured. The designed circuitry consists of five SONAR ranging modules from which four modules are placed at the corners of the vehicle to keep an eye on the blind corners and one at the front of the vehicle. This SONAR is used to determine the exact position of the obstacle and gather range information from all around the car. The other circuitry which could detect accident, searched the location of accident and sent a massage on predefined numbers automatically. Application of this system significantly determines the accident site. Location detection and transmission of information are fully automated which win valuable rescue time. This paper is organized as follows introduction, novelty, methodology, hardware sections and implementation, software, results and conclusion.

\section{Novelty}

A smart phone based accident system is proposed by Thompson [3]. However smart phones are very expensive and due to false alarm filter it may not detect all accident. Accident detection by utilizing an impact sensor reporting system by wireless module is proposed by R.K Megalingam [4]. But a wireless reporting infrastructure is very expensive and difficult to implement as installation of repeated receives on the road at a very short interval are required. In [5] and [6], no accident alerting system is available in the circuitry. In contrast, our system includes alarm alert system which will give warning to driver to slow down his speed when distance becomes less than threshold. This will reduce the chances of accident.

\section{Methodology}

The system is working in four steps: alarming system, initialization of message circuitry, detection and information transmission. Figure 1 and Figure 2 show the work flow of our detection part.

\subsection{Alarming System}

The designed circuitry consist of five SONAR ranging modules from which four modules placed at the corners of the vehicle to keep an eye on the blind corners and one at the front of the vehicle. This SONAR is used to determine the exact position of the obstacle and gather range information from all around the vehicle. SONAR emits short, high frequency sound pulses at regular intervals. The minimum detection distance which ranges between $15 \mathrm{~cm}$ to $35 \mathrm{~cm}$ [7]. When the distance is less than this range, an alarm turns "ON" so that the driver get beware of accident.

\subsection{Initialization of Messaging Circuitry}

This system will be installed in the vehicle. LCD (Liquid Crystal Display) is attached adjacent to dash board from where the proper working condition of the system can be observed. The system will start automatically when the vehicle is ignited. The circuit will get power supply from the battery of vehicle and we can use separate battery too. Total voltage needed for circuit is $1 \mathrm{~V}$ voltage regulators are used for distribution of supply voltage. GSM needs 4.2 V for operation. LM317 with the combination of a resistor and regulator knob is used for 


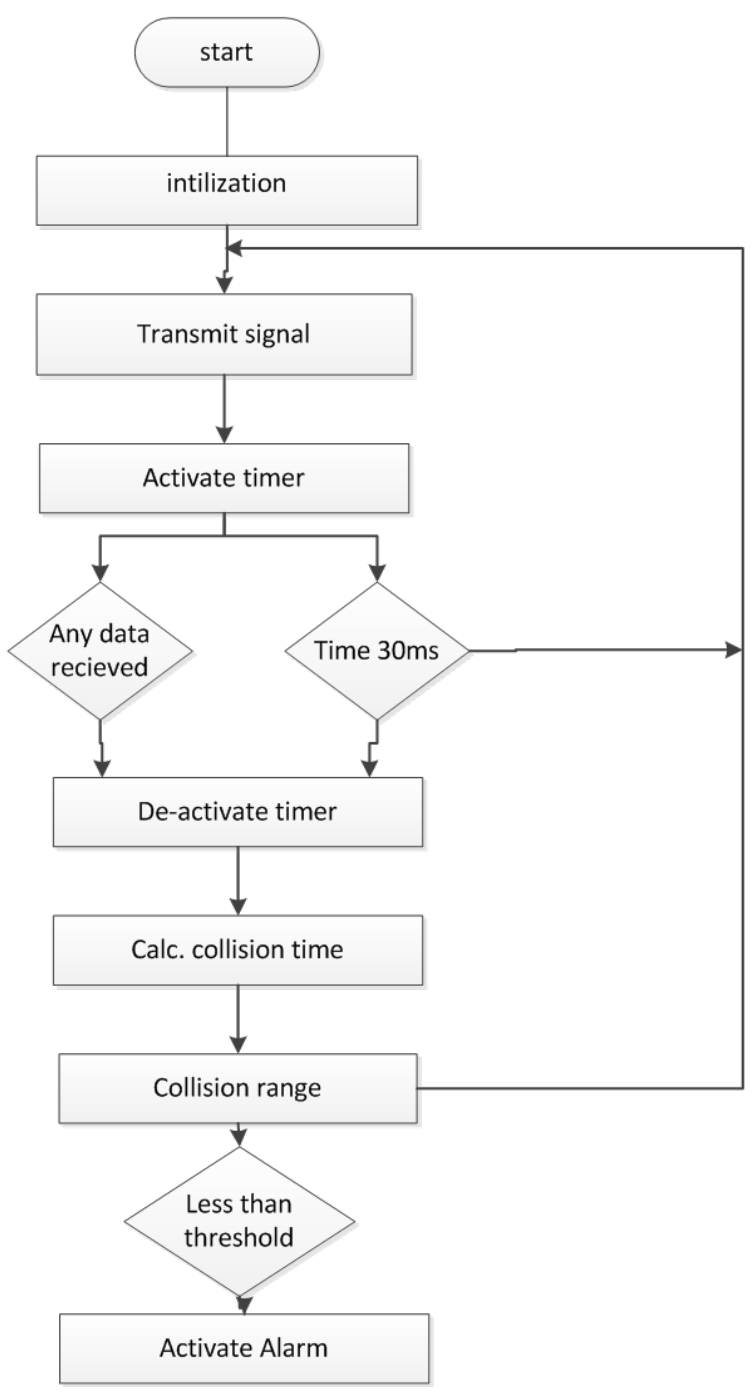

Figure 1. Work flow of our detection system.

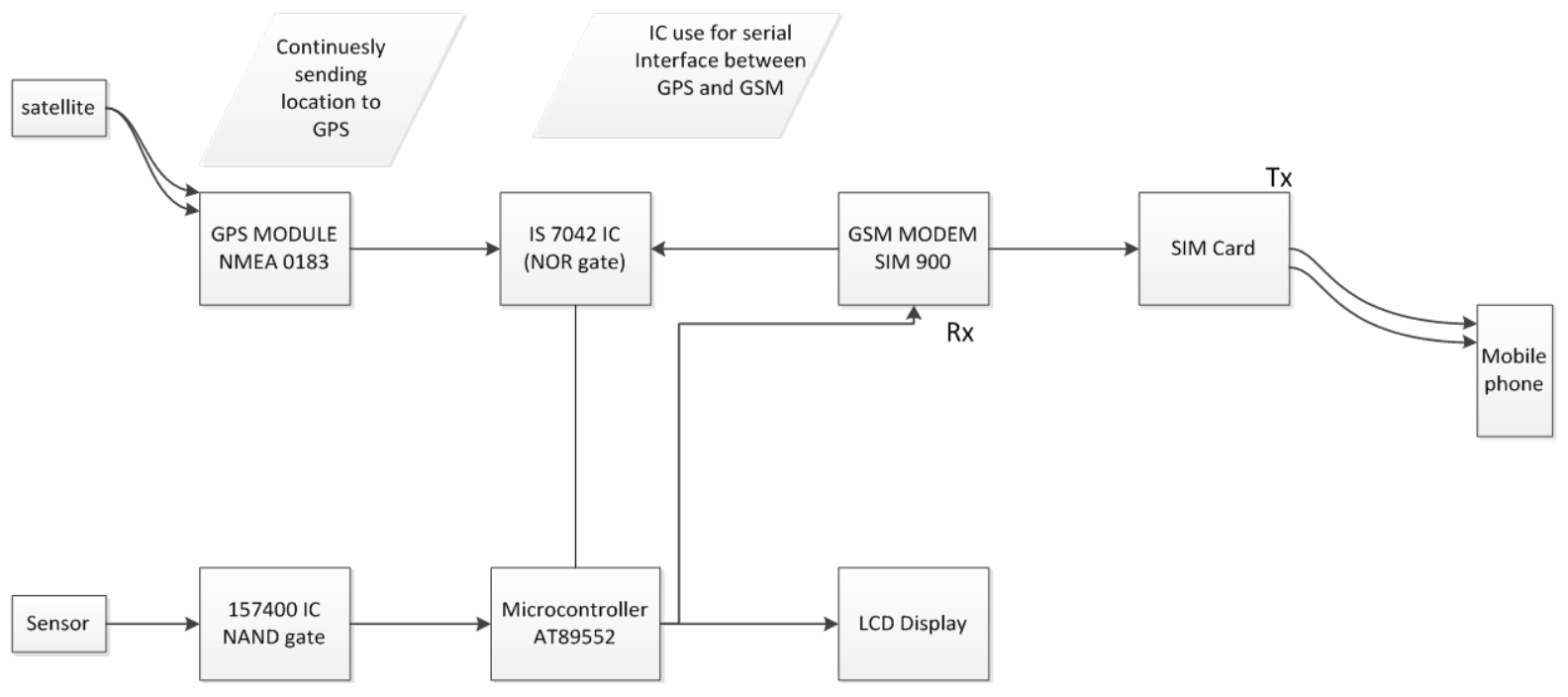

Figure 2. Work flow of message transmitting system. 
providing the desired voltage which is needed. $5 \mathrm{~V}$ are needed for operation of LCD, GPS, Microcontroller, 7402IC (NOR gates) and 7400IC (NAND gates) which is provided by 7805 voltage regulator. The network status pin does depict the status of accessing network and GPS antenna will be attached with window. So GPS can get signals continuously from satellite. GPS will take approximate same value with in distance of 40 meters. However value of location will be different in decimals during testing when we move system on adjacent locations. Whatever location is detected by GPS, it will be displayed on LCD.

\subsection{Detection}

Vibration sensor is connected with microcontroller through 7400IC. When collision of vehicle occurs, vibration sensor will sense the immense vibration. One of the inputs of NAND gate will goes high. It sends interrupt to microcontroller.

\subsection{Transmission of Information}

When Microcontroller will receive interrupt it will enable the GSM modem. It will send SMS on predefine numbers already store in microcontroller. When information will send through message "sending SMS (Short Message Service)" statement will be showed on LCD (Figure 3).

\section{Hardware Section and Its Implementation}

Hardware sections used in our detection system includes GPS modem, GSM modem, alarm module, microcontroller and vibration sensor.

\subsection{Sonar Sensor}

An ultra-sonic sensor transmits ultrasonic waves in the air and detects the reflected waves from surrounding objects. Ultrasonic sensor generates high frequency sound waves and evaluates the echo which is received back by the sensor. Sensor calculates the time interval between sending the signal and receiving the echo to determine the distance to an object. It uses very high frequency inaudible to humans. Sonar emits short, high frequency sound pulses at regular intervals. These propagate in the air at the frequency of sound. The minimum detection distance which ranges between $15 \mathrm{~cm}$ to $35 \mathrm{~cm}$ [7]. SRM-401 is SONAR ranging module standard that utilizes a SONAR ranging IC (PW0268) for ranging purpose.

\subsection{GPS}

The Global Positioning System (GPS) is a popular technology which was developed by American Department of Defense (DOD) for military use. Later on it was available for civilian use. It can be utilized for wide range of applications such as location, direction, speed, timing, surveying, logistic traffic management, security etc.

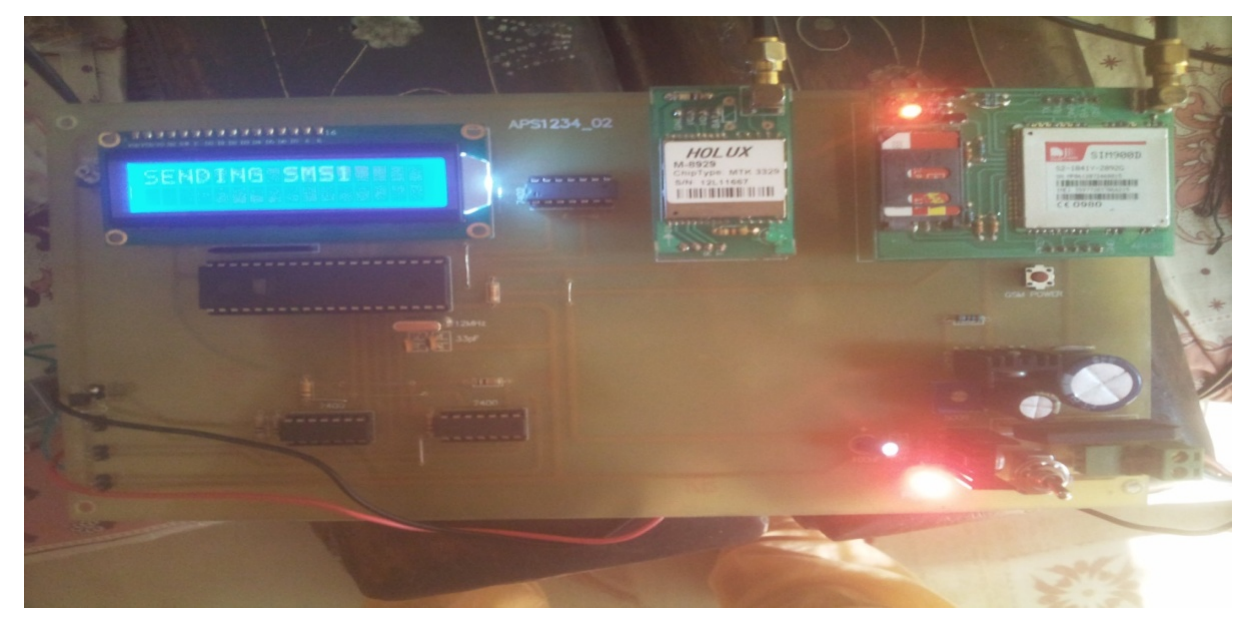

Figure 3. Physical realization of system. 
Nowadays, it became an integral part of a vehicle system for tracking and navigation speed [8]. Each GPS satellite transmits data that indicates its location. All GPS satellites synchronize operations so that these repeating signals are transmitted at the same instant. The signals (moving at the speed of light) arrive at a GPS receiver at slightly different times because some satellites are further away than others. The distance to the GPS satellites can be determined by estimating the amount of time it takes for their signals to reach the receiver. When the receiver estimates the distance from at least four GPS satellites, it can calculate its position in three dimensions. In this system the GPS protocol National Marine Electronics Association (NMEA)-0183 is used.

The sensor for the location detection is the GPS receiver [9]. A very sensitive and accurate GPS signal acquiring device is required for the system. Its 20 parallel channels and 4000 search bins provide fast satellite signal acquisition and short setup time which is $<8$ seconds in hot start and $<40$ seconds in cold start. Tracking sensitivity of $-159 \mathrm{dBm}$ offers good navigation performance even in urban areas [10].

\subsection{GSM}

GSM modem is similar to mobile phone without any display, keypad and speakers. This accepts a SIM card, and operates over a subscription to a mobile operator. GSM modem can accept any GSM network operator SIM card and act just like a mobile phone. More than 690 mobile networks provides GSM services across 213 countries and GSM represents $82.4 \%$ of all global mobile connections [11]. Besides the voice communication it also offers short messages services (SMS) and General packet radio services (GPRS) to transfer data. GSM digitizes and compresses data, then sends it down a channel with two other streams of user data, each in its own time slot. It operates at either the $900 \mathrm{MHz}$ or $1800 \mathrm{MHz}$ frequency band, in addition there are two others frequency bands but most common are mentioned above. The transmission rate of GSM is $270 \mathrm{kbps}$. The GSM modem utilized the GSM network to send the location of the accident. The modem can be controlled by the microcontroller.

The GSM modem has capacitors and resistors for their proper working and LEDs for indicating the network status. The network status pin does depict the status of accessing network right away when we turn the circuit "ON". To represent it we used a green LED whose status will be that it will blink rapidly when like to acquire network and blink slowly after the assessment of network.

\subsection{Control Unit}

Atmel AT89S52 microcontroller is used for our control unit and it is a heart of detection system. It receives data from the GPS, processes all data and detects the accident location from processed data. Location of accidents also sends by microcontroller. ATMEL AT89S52 is a high performance low power $8 \mathrm{k}$ bytes microcontroller of in-system programmable flash memory. The device is manufactured using Atmel's high density nonvolatile memory technology and is compatible with the industry standard 80C51 instruction set. The on-chip flash allows the program memory to be reprogrammed in system or by a conventional nonvolatile memory programmer. AT89S52 is a powerful microcontroller which provides a highly flexible and cost effective solution to many embedded control applications.

\section{Software}

The software used is Keil $\mu$-Vision is a Windows based front end for the C Compiler and Assembler. $\mu$-Vision IDE (Integrated Development Environment) allows developers to create embedded applications using the Keil development tools. Keil Software provides you with software development tool for the 8051 family of microcontrollers [12]. With these tools; you can generate embedded applications for the multitude of 8051 derivatives.

Proteus VSM allows professional engineers to run interactive simulations of real designs, and to reap the rewards of this approach to circuit simulation. Proteus 6 Professional separated into two main components, which are ISIS 6 Professional and ARES 6 Professional. ISIS 6 Professional mainly involved on circuit designing and simulation.

Code for this system is written in assembly language in Keil (Appendix). Then we connect our circuit on Proteus and burned the code from Keil on microcontroller and simulate the circuit in Proteus for verification that the system is working properly or not (Figure 4).

\section{Results and Conclusions}

An automatic accident prevention and reporting system is designed and implemented using wireless technolo- 


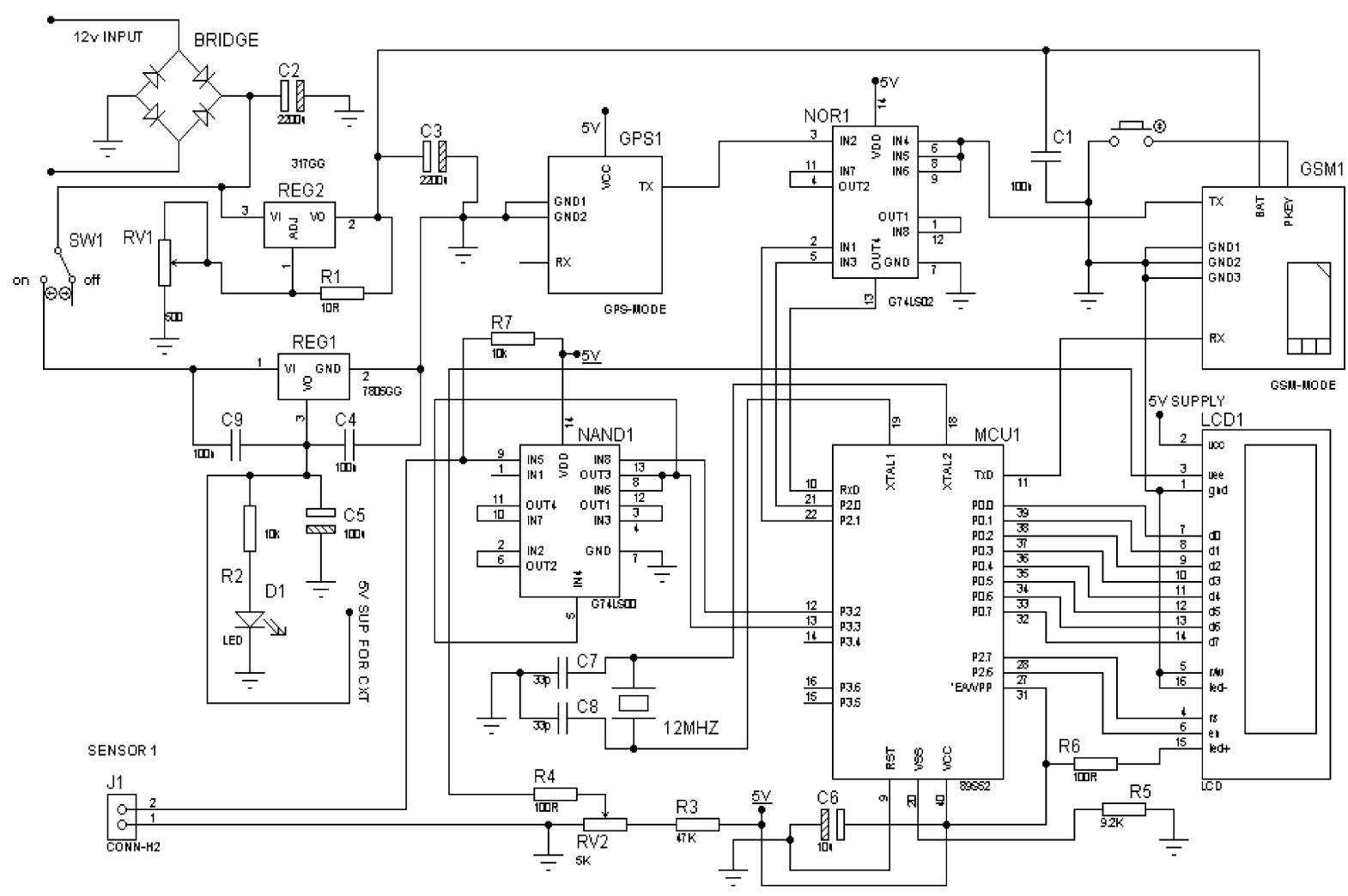

Figure 4. Hardware connection of messaging system.

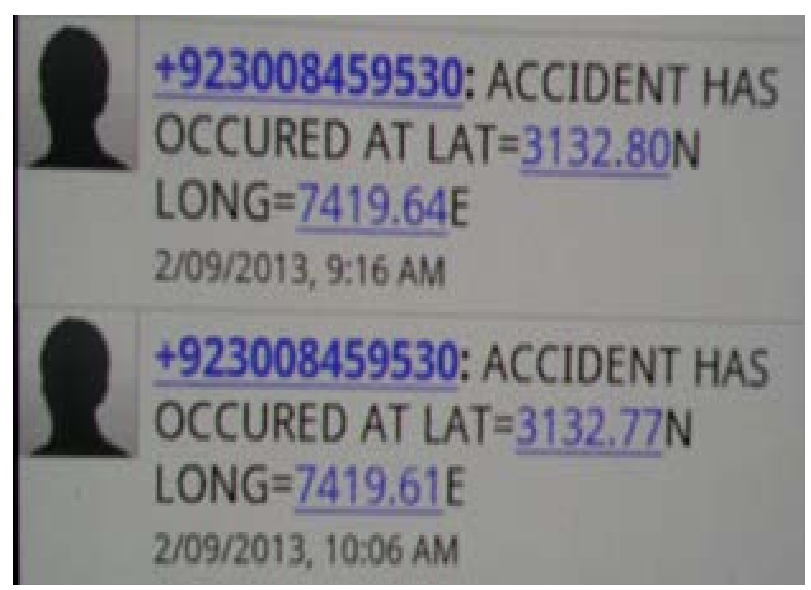

Figure 5. Snapshots for alert messages for accident detection.

gies like SONAR to prevent accident, GPS modem for finding the location of vehicle in terms of latitude and longitude, as well as GSM for sending message on mobile at the receiver end. As we conclude our paper here along with the entire stimulus, we are still willing to upgrade the application of enhanced technology for the electronic equipment usage efficiency.

The snapshot indicates the messages alerts when our accident alert system is tested at two different locations near to one another. Hence, there is a small variation in the coordinates, the initial value of latitudes and longitudes are same but the fractional value changes with small difference. The first SMS shows that the testing accident has occurred at latitude of value 3132.80 along North direction and longitude of value 7419.64 along East direction. The second SMS is representing the values of latitude and longitude as 3132.77 North and 7419.61 East respectively (Figure 5). 


\section{References}

[1] Malik, A.S., Boyko, O., Atkar, N. and Young, W.F. (2001) A Comparative Study of MR Imaging Profile of Titanium Pedicle Screws. Acta Radiologica, 42, 291-293. http://dx.doi.org/10.1080/028418501127346846

[2] Khan, A.M. and Tehreem, A. (2012) Causes of Road Accidents in Pakistan. Journal of Asian Development Studies, 1.

[3] Thompson, C., Whit, J., Doughenty, B., Abnight, A. and Schmidt, D.C. (2010) Using Smart Phone to Detect Car Accidents and Provide Situational Awareness Emergency Responses. The 3rd International ICT Conference on Mobile Wireless Middleware Operating Systems and Applications.

[4] Megalingam, R.K., Nair, R.N. and Pakhya, S.M. (2010) Wireless Vehicular Accident Detection and Reporting System. International Conference on Mechanical and Electrical Technology (ICMET).

[5] Syedul Amin, Md., Bhuiyan, M.A.S., Reaz, M.B.I. and Nasir, S.S. (2013) GPS and Map Matching Based Vehicle Accident Detection System. 2013 IEEE Student Conference on Research and Development (SCOReD), Putrajaya, 16-17 December 2013.

[6] Varma, S.K.C., Poornesh, Varma, T. and Harsha (2013) Automatic Vehicle Accident Detection and Messaging System Using GPS and GSM Modems. International Journal of Scientific \& Engineering Research, 4.

[7] Rana, U. Accident Prevention System. Department of Electrical Engineering, Lahore College for Women University.

[8] Thakor, N., Vyas, T. and Shah, D. (2013) Automatic Vehicle Accident Detection System Based on ARM \&GPS. International Journal for Research in Technological Studies, 1.

[9] Ramadan, M.N., Al-Khedher, M.A., Senior Member, IACSIT and Al-Kheder, S.A. (2012) Intelligent Anti-Theft and Tracking System for Automobiles. IEEE.

[10] Agilent Technologies (2010) GPS Technology Concept.

[11] Japheth, D. (2013) Geographic Information System-A Tool for Sustainable Develeopment of the Nigeria Environment: Global System for Mobile Communication. Journal of Environmental Research and Development, 8.

[12] Mazidi, M.A. and Mazidi, J.G. The 8051 Microcontroller and Embedded Systems. Pearson Education, Prentice Hall Publication, Upper Saddle River. 


\section{Appendix}

LCD is connected at Port 0 of Microcontroller LCDDATA EQU P0

Pin 2.0 is selecting GSM SEL_GSM BIT P2.0

Pin 2.1 is selecting GPS

$$
\text { SEL_GPS BIT P2.1 }
$$

Pin 3.3 is connected to Sensor $\begin{array}{lll}\text { SENSOR } & \text { BIT } & \text { P3.3 }\end{array}$

Set 4800 BAUD RATE

Loop of circuit operation started START:

Reading GPS data (latitude and longitude) ACALLREAD_GPS

Display the observed coordinates ACALLDISPLAY_GPS

\section{Initialize GSM}

ACALLGSM

Jump to LOOP3 if sensor does not sense any vibration JNB SENSOR, LOOP3

Jump to SMS_ACCIDENT ACALLSMS_ACCIDENT

Clear and reset the previous condition

$$
\text { CLR S_RESET }
$$

SETB S_RESET

Jump to START for starting the procedure again LOOP3: SJMP START

Set that GPS data is to be displayed DISPLAY_GPS:

LCD line 1 is selected for displaying GPS data ACALLLCD LINE1
GSM START HERE

RAM of GSM modem is cleared ACALLRAM_CLEAR

IF THERE IS A NEW MSG

DB “AT + CMGL = 0”, CR, LF, 0

Display about New Message DB “NEW MESSAGE.”, 0

Select Text Mode for GSM

$\mathrm{DB} \quad$ “AT + CMGF = 1", CR, LF, 0

Select SIM for SMS

DB “AT + CPMS = ”, 34, “ME”, 34, CR, LF, 0

Read SMS from Location 1

$\mathrm{DB} \quad$ “AT + CMGR = 1”, CR, LF, 0

SMS_ACCIDENT:

Define the data "ACCIDENT HAS OCCURED AT" DB “ACCIDENT HAS OCCURED AT”, 0

Jump to LCD_PRINT

ACALLLCD_PRINT

Display about SMS sending on LCD DB “SENDING SMS1", 0

Configure GSM to Text mode $\mathrm{DB} \quad$ “AT $+\mathrm{CMGF}=1 ”, \mathrm{CR}, \mathrm{LF}, 0$

Enable SMS sending mode of GSM DB “AT + CMGS = ”, 34, “03074013945”, 34, CR, 0

Second SMS is sending

DB “SENDING SMS2", 0

Give command to LCD for display the description about accident LCD_PRINT: POP DPH

Command to LCD for Exiting from loop LCD_EXIT: MOV A,\#1 
Scientific Research Publishing (SCIRP) is one of the largest Open Access journal publishers. It is currently publishing more than 200 open access, online, peer-reviewed journals covering a wide range of academic disciplines. SCIRP serves the worldwide academic communities and contributes to the progress and application of science with its publication.

Other selected journals from SCIRP are listed as below. Submit your manuscript to us via either submit@scirp.org or Online Submission Portal.
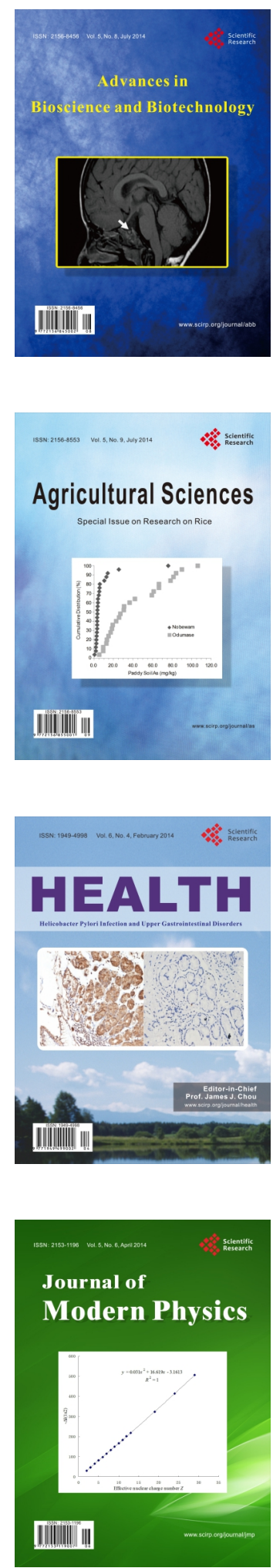
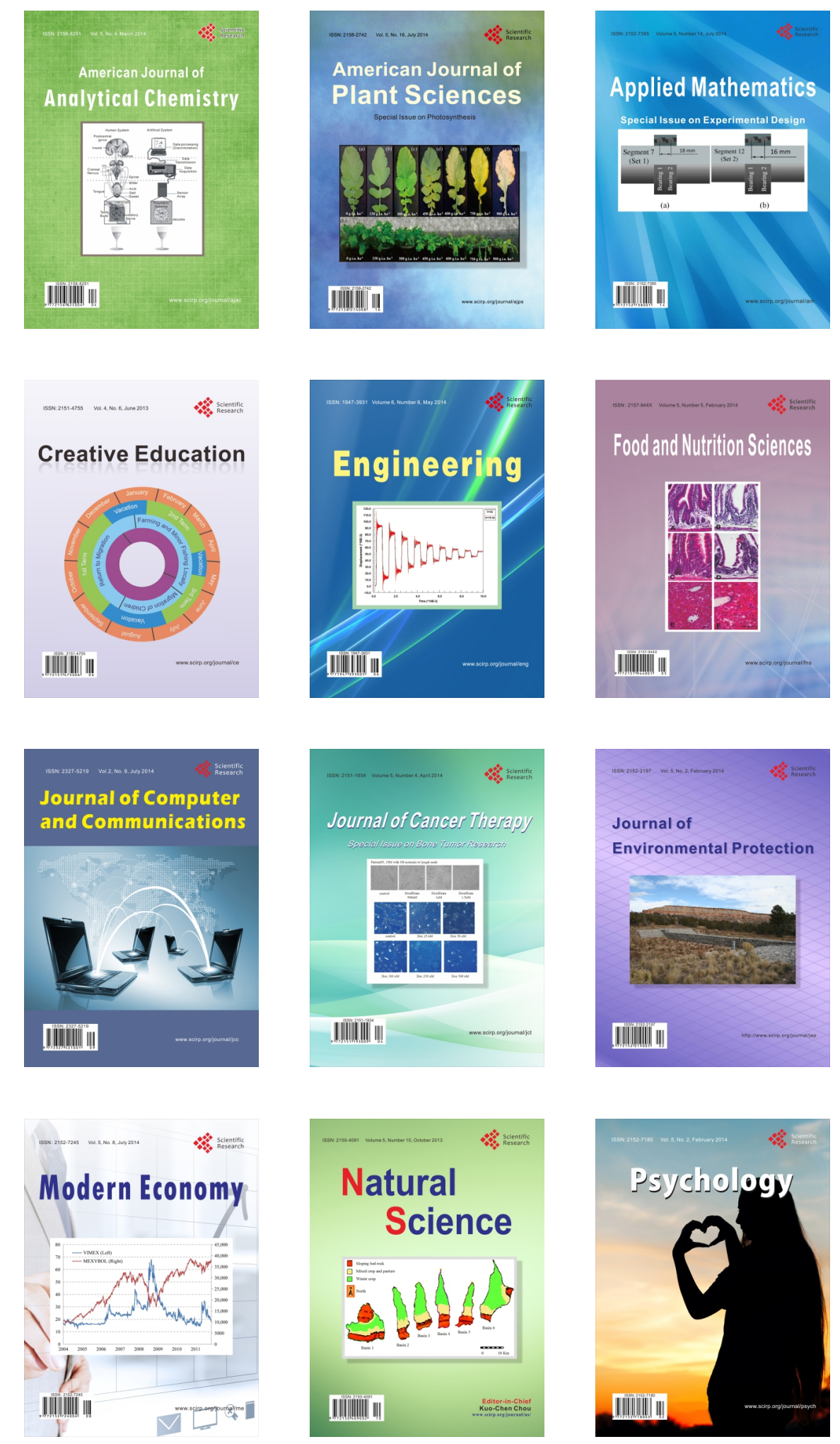